\title{
Inheritance of Bilateral Fusion of the Lower Central and Lateral Incisors: A Pedigree of a Maya Family from Yucatan, Mexico.
}

\author{
Francisco D. Gurri* and Gilberto Balam² \\ ${ }^{1}$ Departmento de Población y Ambiente, El Colegio de la Frontera Sur-Unidad Campeche, and ${ }^{2}$ Cinvestav-Unidata \\ Merida, Cordemex, Merida Yucatan, Mexico
}

\begin{abstract}
A pedigree with five individuals exhibiting bilateral fusion of lower central and lateral incisors is described. It is the first pedigree ever published presenting this condition, and the individuals affected are the 6th through 10th cases in the literature. Bilateral fusion of the lower central incisors may be the consequence of an autosomal dominant gene in this family. Crown height and mesiodistal measurements on the permanent dentition of the affected individuals were compared to the same measurements taken on
\end{abstract}

Double teeth have been described in the literature as the result of two developmental events taking place during the bud stage of tooth formation. These events are called gemination and fusion. The term gemination is described as an attempt at formation of two teeth from a single tooth bud, and fusion is the joining together of two teeth (Shafer et al., 1974; Pindborg, 1970; Grahnen and Granath, 1961). This being the case, gemination can more accurately be described as the result of an incomplete bifurcation of a single tooth bud at the early stages of development. Fusion, on the other hand may result from the union of the epithelial cells of two different tooth buds, which will later develop into a single mesiodistally enlarged tooth.

Both fused and geminated teeth may share an enlarged pulp chamber and a single root canal, or may have separate root canals or bifurcated pulp chambers (Maibaum, 1990; O'Reilly, 1990; Hosomit et al., 1989; Reeh and El Deeb, 1989; Levitas, 1965). As a consequence, the identification of double teeth as geminated or fused teeth based on their shape is difficult, even when using radiographs. Furthermore, some authors have argued that since both fusion and gemination are developmental processes that cannot be observed and that, to avoid confusion, they should not be separated for analysis (Killian and Croll, 1990; Mader, 1979; Brook and Winter, 1970). In fact, the only practical way to classify them is by counting the double tooth as a single one. If the dental arch contains a normal set of teeth, the double formation is classified as gemination. On the other hand, if a tooth unaffected persons in their population. Buccolingual and mesiodistal measurements on the deciduous dentition were compared to published means for populations around the world. Fusion was associated with a genetic tendency towards tooth reduction, affecting tooth number in the jaw, and overall size. It also was concluded, as suggested by previous investigators, that fusion and gemination are under separate genetic control. Dental Anthropology 2006;19(1):29-34.

is missing, the event is classified as fusion (Pindborg, 1970; Levitas, 1965). This approach is far from perfect since the synchronous presence of gemination, fusion, supernumerary teeth, and congenitally missing teeth could lead to misclassifications.

Moody and Montgomery (1934) suggested that the formation of double teeth is under genetic control. Since then, data supporting their hypothesis have continued to mount in human and nonhuman cases. For instance, double teeth have been encountered in a strain of Lakeland terriers (Hitchin and Morris, 1966) and in human twins (Nik-Hussein and Salcedo, 1987; Dixon and Stewart, 1976; Grahnen and Granath, 1961). Trait frequencies vary among populations, being most common among people of Asian and Amerindian origins (Bedy and Moody, 1992; Barac and Skrinjaric, 1991; Skrinjaric and Barac, 1991; Ishida et al., 1990; Salem, 1989; Hagam, 1988; Stevenson, 1983; Brook and Winter, 1970; Pindborg, 1970; Curzon and Curzon, 1967; Grahnen and Granath, 1961; Saito, 1959). There has been disagreement, however, as to the mode of transmission of double teeth. Dixon and Stewart (1976), based on Moody and Montgomery (1934), and Hitchin and Morris (1966) proposed that double teeth may involve Y-linked or holandric transmission. Saito

Correspondence to: Francisco D. Gurri, El Colegio de la Frontera Sur-Unidad Campeche, Calle 10 No. 264, Colonia Centro, Campeche, Campeche, Mexico, 24000, E-Mail: fgurri@camp.ecosur.mx 
(1959) studied 7,589 infants and 2,740 older children from 141 families with at least 1 affected individual. He considered both fused and geminated teeth as double teeth, and concluded that the trait follows a simple mendelian segregation ratio, and "double teeth" is due to a dominant gene with $73.8 \%$ penetrance in the primary dentition, $62.3 \%$ penetrance in the permanent, and $90.2 \%$ for both.

Double teeth most commonly involve (1) the central and lateral incisors and (2) the lateral and the canine, and they are more common in the primary dentition (Grahnen and Granath, 1961; Pindborg, 1970; Ishida et al., 1990; Duncan and Helpin, 1987). They also are more common in the mandible than the maxilla (Brook and Winter, 1970). Finally, they are just as likely to be found in males as in females (Jarvinen et al., 1980).

In an effort to predict tooth number in the permanent dentition from the primary dentition, Gellin (1984) investigated two independent relationships. First he found that there were associations between oligodontia, microdontia, and fusion. He then confirmed associations between supernumerary teeth, macrodontia and gemination. In addition, he found that while in all cases the teeth involved are the incisors and the canines, fusion (along with oligodontia) occurs predominantly in the lower jaw. In contrast, gemination and supernumerary teeth are usually found in the maxilla arch. These tendencies had already been reported by Pindborg (1970), and later studies have supported these results (Barac and Skrinjaric, 1991; Skrinjaric and Barac, 1991; Ishida et al., 1990; Hagam, 1988 ).

Duncan and Helpin (1987) reviewed the cases on bilateral fusion and gemination published in the literature up to 1987. Cases reported by Bricker and Martin (1987), Maibaum (1990) and Nik-Hussein (1989) were added to these and are summarized in Table 1 . As may be observed, bilateral fusion and gemination follow

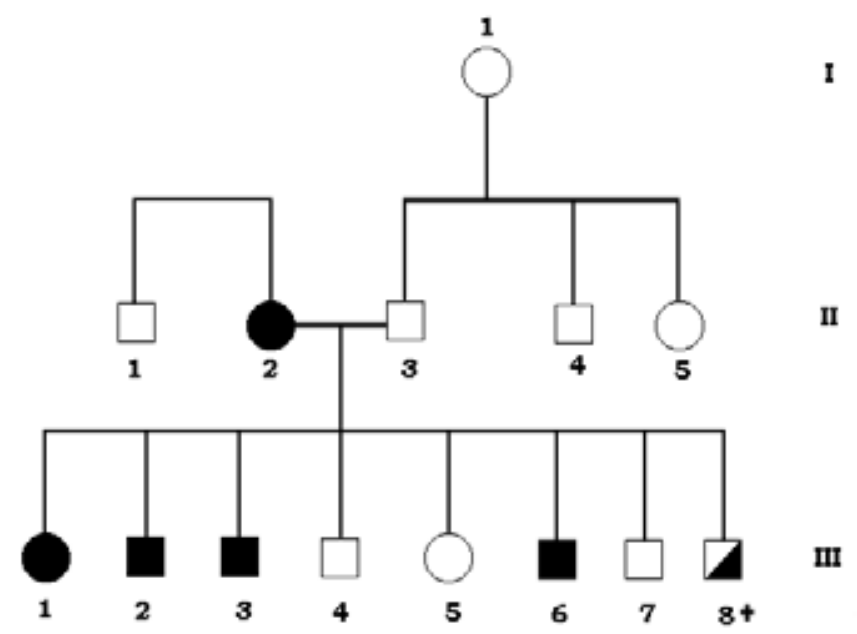

Fig. 1. Pedigree of mandibular fusion of central and lateral incisors in a Yucatecan Maya family (symbols for affected individuals are filled in).

the observed patterns as their unilateral counterparts. The most commonly affected teeth in both situations are the incisors and the canines. Gemination, both in the primary and secondary dentition, is predominantly a feature of the maxillary dentition, while fusion is more common in the mandible, especially in the primary dentition. Fusion in the lower jaw, as in the unilateral cases, is accompanied by what could be considered oligodontia, while gemination is often associated with a supernumerary tooth.

These differences suggest that fusion and gemination result from independent events. Fusion may be associated to a mandibular process of tooth reduction and gemination to a maxillary process of tooth enlargement and increment in number. This being the case, the two processes may be under different genetic control, and regarding them as one may have hindered previous attempts to estimate the mode of inheritance

TABLE 1. Total cases of bilateral fusion or gemination reported in the literature

\begin{tabular}{|c|c|c|}
\hline Condition & Location & Teeth \\
\hline Gemination primary dentition & $75 \%$ maxilla & Central and lateral incisors. \\
\hline Gemination permanent dentition & $100 \%$ maxilla & Central incisors. \\
\hline Fusion primary dentition & $92.3 \%$ mandible & $\begin{array}{l}61.53 \% \text { lateral incisors and } \\
\text { canines. } 38.46 \% \text { central and } \\
\text { lateral incisors. }\end{array}$ \\
\hline Fusion permanent dentition & $\begin{array}{l}57.14 \% \text { mandible, } \\
42.85 \% \text { maxilla }\end{array}$ & $\begin{array}{l}1 \text { lateral incisors and canines. } \\
5 \text { central incisors and } \\
\text { supernumerary (maxilla). } \\
4 \text { central and lateral incisors. } \\
2 \text { lateral incisors and canines. }\end{array}$ \\
\hline
\end{tabular}


TABLE 2. Crown height percentiles in mm. for Yucatecan Maya populations

\begin{tabular}{|c|c|c|c|c|c|c|c|c|c|c|c|c|c|c|}
\hline \multirow[b]{3}{*}{ Tooth } & \multicolumn{7}{|c|}{ Males ages 10 to 15 years old } & \multicolumn{7}{|c|}{ Females ages 30 to 40 years old } \\
\hline & \multicolumn{7}{|c|}{ Percentile } & \multicolumn{7}{|c|}{ Percentile } \\
\hline & $\mathrm{n}$ & 5 & 25 & 50 & 75 & 95 & C6 & $\mathrm{n}$ & 5 & 25 & 50 & 75 & 95 & B6 \\
\hline LI1 & 100 & 7 & 8 & 8 & 9 & 10 & 6 & 77 & 6 & 7 & 8 & 9 & 10 & 8 \\
\hline RI1 & 99 & 7 & 8 & 8 & 9 & 10 & 6 & 76 & 6 & 7 & 8 & 9 & 10 & 8 \\
\hline LC & 90 & 6 & 7 & 7 & 8 & 9 & 6 & 92 & 6 & 7 & 8 & 8 & 10 & 7 \\
\hline $\mathrm{RC}$ & 90 & 6 & 7 & 7 & 8 & 9 & 6 & 91 & 6.6 & 7 & 8 & 8 & 10 & 6 \\
\hline
\end{tabular}

of double teeth.

The present paper presents the 6th through 10th cases of bilateral fusion of the lower central and lateral incisors as near as can be determined. They were all detected in a single family, which makes this the first published pedigree of bilateral fusion. It would seem to be useful to determine the mode of inheritance of this pedigree.

\section{MATERIALS AND METHODS}

During 1992, in the town of Zavala, located in the Maya region, state of Yucatan, Mexico, a family was examined as part of a survey on the frequency of enamel hypoplasia (Gurri and Balam, 1992). Upon inspection of the mother's dentition, it was noted that she exhibited bilateral fusion of the lower central and lateral incisors. Her children and husband where then examined, and it was observed that 4 of her offspring also exhibited the trait (Fig. 1). In a subsequent visit, hydrocolloid impressions and plaster casts were made of all affected individuals except for a 1.5 year old child with a very small dental arch. Attempts were also made to locate all living relatives.

The casts were analyzed in the dental laboratory in the Department of Anthropology of Indiana University. Discrimination between fusion and gemination was based on counting the anomaly as one tooth, and summing the total number of teeth in the dental arcade
(Pindborg, 1970; Levitas, 1965).

To test for the presence of microdontia, the crown height measurements of individuals II2 and III6 where compared to the local population. Crown heights on the permanent upper central, lower central incisors and lower canines were taken in this population as part of the research on enamel hypoplasia. However, no measurements were taken on the deciduous dentition. The mesiodistal and buccolingual dimensions of the upper central incisors, and the upper and lower canines of individuals III 2 and III 3 were compared to measurements published by Grine (1986) for different populations around the world.

Measurements in the Maya population were taken in vivo with a plastic vernier caliper and recorded to the nearest millimeter. Measurements on the subject family were obtained from plaster casts with the same instrument.

\section{RESULTS}

The pedigree in Figure 1 shows the results. The trait appeared in the mother (II2 Fig. 2), the youngest daughter III1, and 3 of the sons (III2, III3, III6; Figs. 3-5). In all, 4 out of 7 live children have bilateral fusion of the central and lateral incisors, 3 in the primary dentition (III1, III2, III3) and 1 in the permanent (III6). The last child had died, and it was impossible to determine his dental condition since the family was unaware of its

TABLE 3. Mesiodistal breadth percentiles in mm. for Yucatecan Maya populations

\begin{tabular}{|c|c|c|c|c|c|c|c|c|c|c|c|c|c|c|}
\hline \multirow[b]{3}{*}{ Tooth } & \multicolumn{7}{|c|}{ Males } & \multicolumn{7}{|c|}{ Females } \\
\hline & \multicolumn{7}{|c|}{ Percentile } & \multicolumn{7}{|c|}{ Percentile } \\
\hline & $\mathrm{n}$ & 5 & 25 & 50 & 75 & 95 & III6 & $\mathrm{n}$ & 5 & 25 & 50 & 75 & 95 & II6 \\
\hline LI1 & 195 & 7 & 8 & 8 & 9 & 9 & 8.6 & 185 & 7 & 7 & 8 & 8 & 9 & 7 \\
\hline RI1 & 191 & 7 & 8 & 8 & 9 & 9 & 8.2 & 183 & 7 & 7 & 8 & 8 & 9 & 7.25 \\
\hline LI1 & 205 & 4 & 5 & 5 & 5 & 6 & 7 & 218 & 4 & 5 & 5 & 5 & 6 & 8 \\
\hline RI1 & 204 & 4 & 5 & 5 & 5 & 6 & 5.25 & 220 & 4 & 5 & 5 & 5 & 6 & 7 \\
\hline LC & 187 & 5.4 & 6 & 7 & 7 & 8 & 6 & 208 & 5 & 6 & 6 & 7 & 7 & 5 \\
\hline $\mathrm{RC}$ & 187 & 5 & 6 & 7 & 7 & 8 & 6 & 209 & 5 & 6 & 6 & 7 & 7 & 5.5 \\
\hline
\end{tabular}


TABLE 4. Mean mesiodistal diameters in the primary dentition of selected groups*

\begin{tabular}{lcccc}
\hline \multicolumn{1}{c}{ Group } & Maxillary & Maxillary & Maxillary & \multicolumn{2}{c}{ Maxillary } \\
I1 & I2 & C & 6.02 \\
South African & 6.47 & 5.32 & 7.08 & 5.88 \\
Japanese & 6.70 & 5.53 & 6.70 & 6.20 \\
Native American & 6.86 & 5.72 & 7.15 & 6.44 \\
Australian Aborigine & 7.40 & 6.19 & 7.41 & 6.04 \\
European Caucasian & 6.60 & 5.46 & 7.04 & 5.92 \\
American Caucasian & 6.40 & 5.24 & 6.88 & 6.08 \\
Average & 6.74 & 5.58 & 7.04 & 6.00 \\
III2 & 6.10 & 5.58 & 6.90 & 6.90 \\
III3 & 6.30 & 5.59 & 7.50 & \\
\hline
\end{tabular}

*(Grine 1986)

existence.

A brother (II1) and a first cousin of the affected mother were found, neither of whom was found to have the condition. Affinal relatives were also available for examination, but, as shown on the pedigree, neither her husband (II3) nor anyone in his family (I1, II4, II5) was affected.

Table 2 shows a crown height percentile distribution for Maya women, ages 30 to 40 , and males, ages 10 to 15 . The 4 crown heights for individual II6, a female age 36, correspond to the 25th, 50th, 25th and 5th percentiles. All of the crown height measurements on individual III6, a 12 year old boy, fell within the 5th percentile of his population.

Table 3 shows mesiodistal percentile distributions for males and females in the local Maya population. Mesiodistal measurements for the lower canines in III6 correspond to the 25th percentile and in II6 to the 5th. The central upper incisors in B6 correspond to the 5th and 25th percentiles, and the mesiodistal dimensions of $\mathrm{C} 6$ correspond to the 50th.

Tables 4 and 5 show the mesiodistal and buccolingual diameters of UI1, UI2, UC and LC for different populations, and for individuals III2 and III3. Except for UI1, whose mesiodistal dimensions are smaller than the average of any of the reference populations, all other teeth appear normal. The buccolingual breadths of III2 and III3, on the other hand, are extremely small. In comparison to the reference populations, III2 and III3 these buccolingual breadths are extremely narrow.

\section{DISCUSSION}

All cases of bilateral fusion encountered here support the observations of Barac and Skrinjavic (1991), Skrinjavic and Barac (1991), Ishida et al. (1990), Hagam (1988), and Gellin (1984). The independence between the processes determining the number of anterior teeth on each jaw is clear. In each case, fusion is only present in the mandible. Tooth size on both upper and lower dentition appears to be affected. As anticipated, fusion is accompanied by an apparent crown size reduction expressed as reduced buccolingual dimensions in the deciduous dentition and lower crown heights in the permanent dentition. Why this should affect both the upper and lower dentition is not clear. Perhaps this lack

TABLE 5. Mean buccolingual diameters in the primary dentition of selected groups*

\begin{tabular}{lcccc}
\hline \multicolumn{1}{c}{ Group } & Maxillary & Maxillary & Maxillary & \multicolumn{2}{c}{ Mandibular } \\
I1 & I & I2 & C & 5.48 \\
African & 4.98 & 4.85 & 6.16 & 6.05 \\
Australian Aborigine & 5.47 & 5.24 & 6.61 & 5.31 \\
Naisoi & 5.15 & 4.79 & 5.91 & 5.6 \\
American Caucasian & 5.13 & 4.71 & 6.11 & 5.61 \\
Mean & 5.18 & 4.90 & 6.20 & 4.75 \\
III2 & 4.60 & 4.25 & 5.50 & 4.20 \\
III3 & 5.00 & 4.20 & 5.60 & \\
\hline
\end{tabular}

*(Grine 1986) 


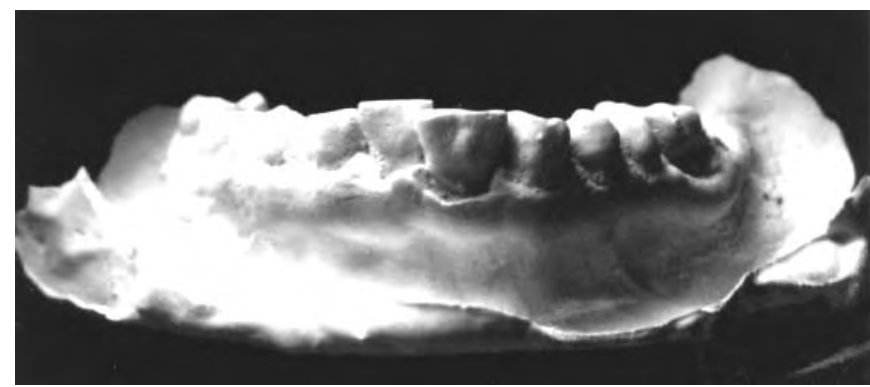

Fig. 2. Fusion of the permanent lower incisors of individual II1 (frontal view).

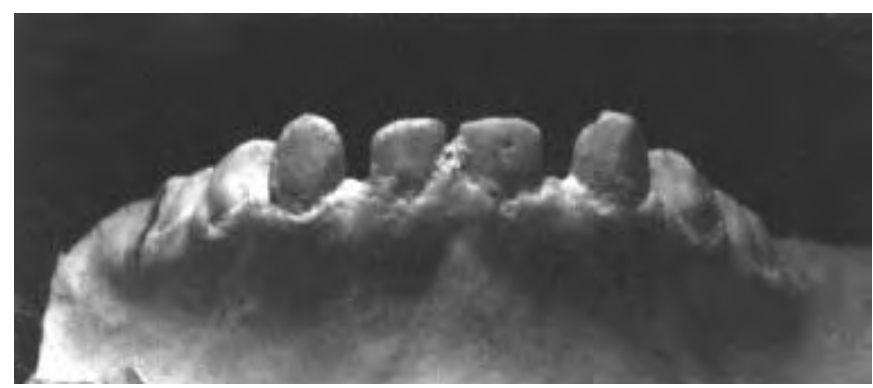

Fig. 3. Fusion of the deciduous lower incisors of individual III3. Fusion is so advanced that, except for the exaggerated mesiodistal width, this case could be mistakenly classified as agenesis of the lateral incisors (frontal view).

of independence between the upper and lower jaws with regard to tooth size is related to the generalized trend towards tooth reduction that accompanies oligodontia (Garn, 1977). If this is the situation, fusion should not only be associated with frontal tooth reduction but third molar agenesis as well.

Although Moody and Montgomery (1934) did not differentiate between fusion and gemination, they described what appears to be unilateral fusion of the lower incisors. The pedigrees they present suggest that inheritance of the trait is controlled by a single dominant gene. However, the fact that their study showed only females inheriting and transmitting this trait make it difficult to establish its autosomal nature. In the study by Saito (1959) - based on a large sample of infants, children and their families - the trait indeed seems to be transmitted as an autosomal dominant character. Saito, however, did not distinguish between fusion and gemination when attempting to establish the mode of inheritance. The attendant confusion of including what may be two different genetic processes may also have led to his inference that the trait exhibited incomplete penetrance.

The pedigree presented in the present paper, however, makes it clear that if bilateral fusion of

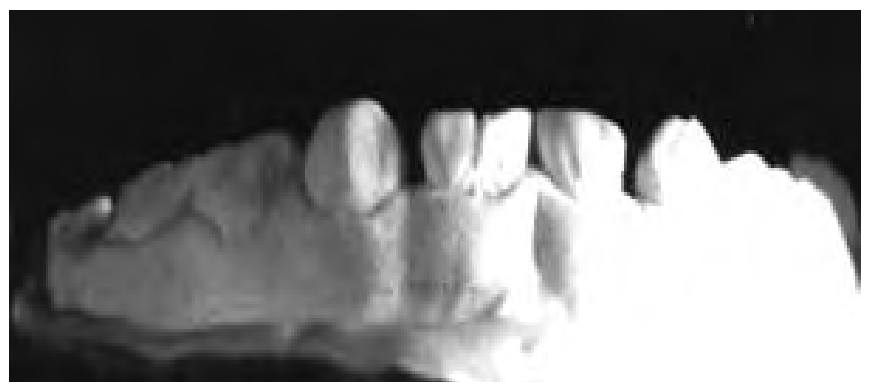

Fig. 4. Fusion of the deciduous incisors of individual III2. His right incisor is the only one that shows some separation in this series (frontal view).

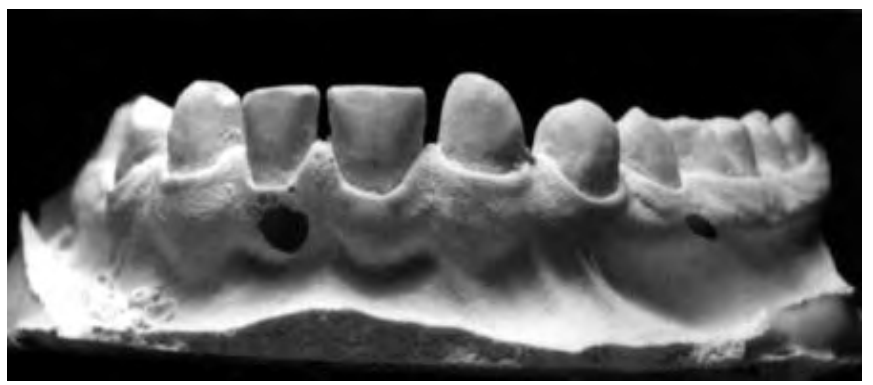

Fig. 5. Fusion of the permanent lower incisors of individual III6 (three-quarter view).

the lower incisors is indeed the consequence of an autosomal dominant gene-as appears to be the casethis pedigree exhibits full penetrance. Unfortunately, the present pedigree lacks a third generation from the side of the family that possesses the trait. The husband of the affected mother is not related to her, as far as could be determined, and no one in his family exhibits the trait. Nevertheless, since the husband (II3) is from the same home town as his affected wife (II2), the possibility of inbreeding and the presence of a rare recessive allele cannot be completely ruled out.

\section{ACKNOWLEDGMENTS}

The authors wish to thank Drs. Della Cook and Robert Meier from Indiana University, Department of Anthropology, for their comments and corrections to the original manuscript. We would also like to thank Dr. Cook for photographing the dental casts, and Dr. Ernesto Rico for making the casts. This investigation was supported by a grant from the Instituto Nacional Indigenista de Mexico.

\section{LITERATURE CITED}

Barac FV, Skrinjaric I. 1991. Double teeth in primary dentition and findings of permanent successors. 
Acta Stomatol Croat 25:39-43.

Bedi R, Moody GH. 1992. A primary double molar tooth in a child with Russell-Silver syndrome. Br Dent J 171:284-286.

Bricker SL, Martin R. 1987. Bilateral gemination of maxillary permanent central incisor. Oral Surg Oral Med Oral Pathol 63:120.

BrookAH, WinterGB.1970. Double teeth: a retrospective study of "geminated" and "fused" teeth in children. Br Dent J 129: 123-130.

Curzon JA, Curzon MEJ. 1967. Congenital dental anomalies in a group of British Columbia children. J Can Dent Assoc 33:554-558.

Dixon GH, Stewart RE. 1976. Genetic aspects of anomalous tooth development. In: Steward RE, Prescott G.H. editors. Oral Facial Genetics. St. Louis: C.V. Mosby Company, p 124-150.

Duncan WK, Helpin ML. 1987. Bilateral fusion and gemination: a literature analysis and case report. Oral Surg Oral Med Oral Pathol 64:82-87.

Garn SM. 1977. Genetics of dental development. In: McNamara JA, editor. The biology of occlusal development. Ann Arbor, Michigan: The Center for Human Growth and Development, p 61-88.

Gellin ME. 1984. The distribution of anomalies of primary anterior teeth and their effect on the permanent successors. Dent Clin North Am 28:6980.

Grahnen H, Granath LE. 1961. Numerical variations in primary dentition and their correlation with the permanent dentition. Odont Rev 12:348-357.

Grine FE. 1986. Anthropological aspects of the deciduous teeth of South African blacks. In: Singer $\mathrm{R}$, Lundy JK, editors. Variation culture and evolution in African populations. Johanesburg: Witwatersand University Press, p 47-83.

Gurri FD, Balam G. 1992. Regional integration and changes in nutritional status in the central region of Yucatan, Mexico: a study of dental enamel hypoplasia and anthropometry. J Hum Ecol 3:417432.

Hagam FT. 1988. Anomalies of form and number, fused primary teeth, a correlation of the dentitions. ASDC J Dent Child 55:359-361.

Hitchin AD, Morris I. 1966. Geminated odontomeconnation of the incisors in the dog its aetiology and ontogeny. J Dent Res 45:575-583.

Hosomit YM, Yaoi M, Sakiyama Y, Toda T. 1989. A maxillary central incisor having two root canals geminated with a supernumerary tooth. J Endod 15:161-163.
Ishida R, Mishima K, Adachi C, Miyamoto A, Ooshima T, Amari E, et al. 1990. Frequency of developmental disturbances of tooth structure. Shoni Shikagaku Zasshi 28:466-485.

Jarvinen S, Lehtinen L, Milen A. 1980. Epidemiologic study of joined primary teeth in Finnish children. Comm Dent Oral Epidemiol 8:201-202.

Killian CM, Croll TP. 1990. Dental twining anomalies: the nomenclature enigma. Quintessence Int 21:571576.

Levitas TC. 1965. Gemination fusion, twinning and concrescence. ASDC J Dent Child 32:93-100.

Mader CL. 1979. Fusion of teeth. J Amer Dent Assoc 98:62-64.

Maibaum WW. 1990. Fusion of confusion? Oral Surg Oral Pathol 69:656-657.

Moody E, Montgomery LB. 1934. Hereditary tendencies in tooth formation. J Am Dent Assoc 21:1774-1776.

Nik-Hussein NN. 1989. Bilateral symmetrical fusion of primary and permanent mandibular lateral incisors and canines. J Pedod 13:378-383.

Nik-Hussein NN, Salcedo AH. 1987. Double teeth and hypodontia in identical twins. ASDC J Dent Child 54:179-181.

O'Reilly PM.1989. Astructural study and ultrastructural study of a fused tooth. J Endod 15:442-446.

O'Reilly PM. 1990. Structural and radiographic evaluation of four cases of tooth fusion. Aust Dent J 35:269-9.

Pindborg JJ. 1970. Pathology of the dental hard tissues. Philadelphia: W.B. Saunders Company.

Reeh ES, El Deeb M. 1989. Root canal morphology of fused mandibular canine and lateral incisor. J Endod 15:33-35.

Saito TA. 1959. A genetic study on the degenerative anomalies of deciduous teeth. Jap J Hum Genet 4:27-54.

Salem G. 1989. Prevalence of selected dental anomalies in Saudi children from Gizan region. Comm Dent Oral Epidemiol 17:162-163.

Shafer WG, Hine MK and Levy BM. 1974. A textbook of oral pathology, 3rd ed. Philadelphia: W.B. Saunders Company.

Skrinjaric I, Barac FV. 1991. Anomalies of deciduous teeth and finding in the permanent dentition Acta Stomatol Croat 25:151-6.

Stevenson DR. 1983. Human skeletal remains in archaeological testing at Guices Creek, Stewart County, Tennessee. Memphis State University Anthropological Research Center Occasional Papers No. 12.

Wong M. 1991. Treatment considerations in a geminated maxillary lateral incisor. J Endod 17:179-181. 